\title{
Electro-thermal Model of a Silicon Carbide Power MOSFET
}

\author{
K. Frifita . K. M'Sirdi, E. Baghaz, A. Naamane, and M. Boussak \\ Aix Marseille Univ, Universite de Toulon, CNRS, LIS, Marseille, France \\ SASV group of LIS UMR CNRS 7020, e-mail: nacer.msirdi@univ-amu.fr
}

\begin{abstract}
This paper proposes an electro thermal model for power silicon carbide (SiC) MOSFET based on the EKV MOSFET structure. The thermal dissipation is modeled as an RC Network. The model is developed for the SiC MOSFET C2M0025120D CREE (1200V, 90A) and integrated in the Psim, Saber and Pspice simulation software libraries for prototyping. The simulation curves are compared with the manufacturers' data-sheet.
\end{abstract}

Keywords: SiC MOSFET, Electro-thermal Model, Psim, Saber, Pspice Model

\section{Introduction}

The use of a silicon carbide ( $\mathrm{SiC})$ for industrial manufacturing power components such as the MOSFET makes it possible to have high performance which satisfy advanced application problems (time response, environmental stresses, heating, power loss reduced). These constraints affect the electrical behavior of the electronic components by the coupling between the electrical and the thermal behaviors. In high power applications, Silicon $(\mathrm{Si})$ circuits are more and more replaced by $\mathrm{SiC}$ MOSFET devices [1]. A first serie of such devices has been proposed by CREE, like the SiC MOSFET C2M0025120D (1200V, 90A) [2]. Simulations are very important in electric systems design. Therefore a good suitable simulation models is required in order to show the faisability of the complex systems $[3,4]$.

In this paper, we propose an electro-thermal model based on the EKV MOSFET scheme $[5,6]$ for a SiC MOSFET C2M0025120D (1200V, 90A) proposed by CREE. The model is implemented in Psim, Saber and Pspice softwares to allow easy development of applications. For validation, the simulation curves are compared to the manufacturers' experimental data (curves of data sheets). The results show that the proposed model is more precise compared to the literature existing models. 


\section{SiC MOSFET Electrothermal Model}

\subsection{Nomenclature}

\begin{tabular}{|c|c|}
\hline$V_{S}, V_{G}$ and $V_{D}$ & Source, Gate and Drain Voltages \\
\hline$L_{D}$ & Drain inductance \\
\hline$L_{G}$ & Gate inductance \\
\hline$L_{S}$ & Source inductance \\
\hline$R_{G}$ & Gate Resistance \\
\hline$C_{G S}$ & Drain-Source Capacitor \\
\hline$C_{D S}$ & Gate-Drain Capacitor \\
\hline$C_{G D}$ & On state MOSFET resistance \\
\hline$R_{D S o n}$ & Phermodynamic voltage \\
\hline$V_{p}$ & MOSFET Transconductance \\
\hline$U_{T}$ & Parameters of the triode region \\
\hline$g_{m}$ & Transistor gate Threshold Voltage \\
\hline$K_{s}$ & Slope Factor of drain source current variation \\
\hline$\lambda$ & Parameter for channel length modulation \\
\hline$\alpha$ and $n$ & Power loss dissipated \\
\hline$V_{t h}$ & MOSFET Jonction temperature \\
\hline$T_{c}$ & The MOSFET commutation frequency \\
\hline$P_{P}$ & MOSFET commutation period \\
\hline$T_{j}$ & \\
\hline$F$ &
\end{tabular}

\section{$2.2 \quad$ Electric Model}

The electrical model of a SiC MOSFET $(25 \mathrm{~m} \Omega, 1200 \mathrm{~V}$ and $90 \mathrm{~A})$ proposed here is based on the EKV's one. The power losses are analysed to estimate and take into account their effect as shown in the equivalent scheme of Fig. 1. $V_{S}, V_{G}$ et $V_{D}$ are respectively the Source, Gate and Drain voltages. It includes 3 parasitic inductances (connected in series with the transistor electrodes $L_{G}, L_{D}, L_{S}$ ) to describe the behaviour at high frequencies and the commutation losses. The resistance $R_{G}$ estimates the gate losses. These inductances and the resistances are used to estimate the power losses during the switching [7-9]. The different variables and parameters $\left(V_{D S}, I_{D S}, R_{d s o n}, \ldots\right)$ of the model vary also in function of the junction temperature [10].

In this model, we used parameters from the datasheet and the others from an optimization (comparison) that was performed by Saber, Psim and PSpice. Fig. 1 shows the EKV deduced scheme for a SiC MOFET developed under the softwares. The EKV model is based on mathematical expressions which accounts for a MOSFET operation in three regions. It is composed of two current sources G1 and G2. For interpolation between these regions of operation, a linear combination of logarithmic functions is used by EKV. 


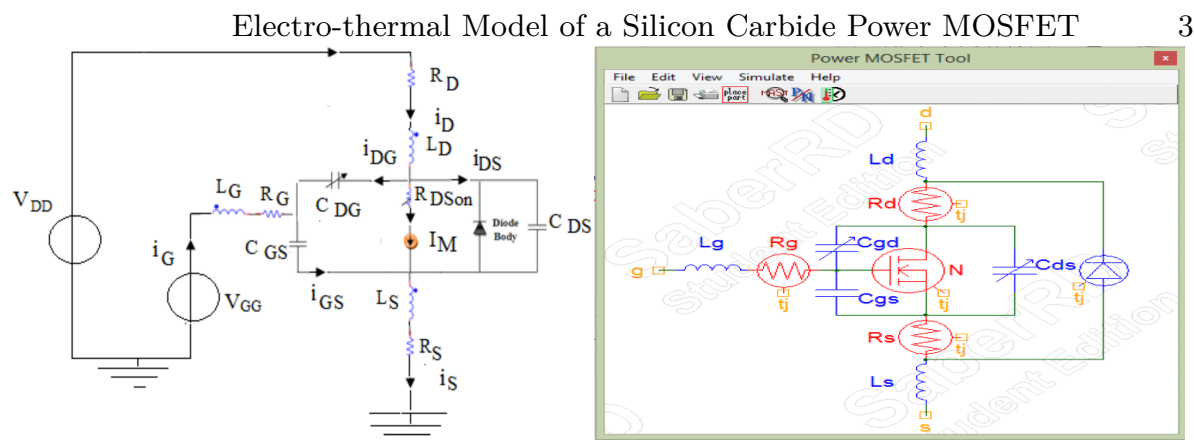

Fig. 1. Electric model of the SiC MOSFET (C2M0080120D) in Saber Software

The specific current is $I_{s_{0}}=2 \cdot U_{t h}^{2} \cdot K_{s} \cdot g_{m}$. The Drain-Source current $\left(I_{D S}\right)$, in the EKV MOSFET model $[7,8]$, is defined by equation 4 , as the difference beetwen the direct $I_{G 1}(2)$ and the reverse one $I_{G 2}(3)[6]$.

$$
\begin{gathered}
I_{M}=I_{G 1}\left(V_{p}-V_{S}\right)-I_{G 2}\left(V_{p}-V_{D}\right) \\
I_{G 1}=I_{s} \cdot g_{m} \cdot\left[\operatorname{Ln}\left(1+\exp \frac{V_{p}-V_{s}}{2 V_{D S}}\right)\right]^{2} \\
I_{G 2}=I_{s} \cdot f t \cdot\left[\operatorname{Ln}\left(1-\exp \frac{V_{p}-V_{D}}{2}\right)\right]^{2} \\
I_{M}=2 \lambda U_{t h}^{2} K_{s} g_{m}\left(\left(L_{n}\left(1+e^{\frac{V_{p}-V_{s}}{2 V_{D S}}}\right)\right)^{2}-f t\left(L_{n}\left(1-e^{\frac{V_{p}-V_{D}}{2}}\right)\right)\right)
\end{gathered}
$$

where $g_{m}$ is the transconductance, $K_{s}$ is the slope factor, $V_{p}=\frac{\left(V_{G}-U_{t h}\right)}{K_{s}}$ the pinch voltage with $U_{t h}$ the thermodynamic reference voltage and $f t$ the internal thermal voltage. This model of Fig. (1) can then be used for simulation and prototyping of any application using this SiC MOSFET into softwares like Saber, Pspice, Psim (see section 3) or Matlab/Simulink (see [11]). The electric equivalent scheme can be completed by electric equations to allow any kind of its numerical simulation.

In a second step, we can consider and include, to this model, the parameters temperature dependance. The accuracy of the proposed model will be enhanced by modeling of the influence of temperature on electrical parameters.

The variation of the junction temperature, leads to parameters variation which can be described as follows, where $\vartheta=-8.5 \mathrm{mV} /{ }^{\circ} \mathrm{K}$. The variations included in the previous model show that the model is Non Linear and Time Varying (NLTV).

$$
\begin{gathered}
V_{G S(t h)}\left(T_{J}\right)=V_{G S(t h)}\left(300^{\circ} \mathrm{C}\right)+\vartheta \cdot\left(T_{j}-300^{\circ} \mathrm{C}\right) \\
g_{m}\left(T_{j}\right)=g_{m\left(300^{\circ} \mathrm{C}\right)}\left(\frac{T_{j}}{300}\right)^{-1.5} \\
R_{D S O N}\left(T_{j}\right)=R_{D S O N\left(300^{\circ} \mathrm{C}\right)}\left(1+\frac{\alpha}{100}\right)^{\left(T_{j-300}\right)}
\end{gathered}
$$

It remains now to describe the temperature variations by a dynamic model which takes into account the MOSFET operation and convert the power losses in heating the component. Thermal dynamic behaviour is obtained using the heat equation and the finite element method. 


\subsection{Thermal Model}

The electro- thermal coupling between the electrical parts and the thermal parts is produced by the power losses $P_{P}$ dissipated during normal operation. This power can be estimated by the following equations $[8,9]$ :

$$
P_{P}=R_{D S o n}(T) \cdot i_{D S}^{2}+\left(0.25 . \Delta t \cdot F \cdot V_{D S} \cdot i_{D S}\right)
$$

We have used the Finite Element Method (FEM) based on an RC Cauer network. As also used in Pspice simulation, we have considered 14 cells of $(R, C)$ equivalent components (Fig.(2) [9]. It gives a very good global approximation of the thermal behaviour going from the MOSFET junction temperature $T_{j}$ to the ambiant air temperature $T_{a}$ (assumed to $25^{\circ} \mathrm{C}$ ), through the case $\left(T_{c}\right)$ (package and the thermal dissipation radiator, $T_{r}$ ) (see Fig.(2)).

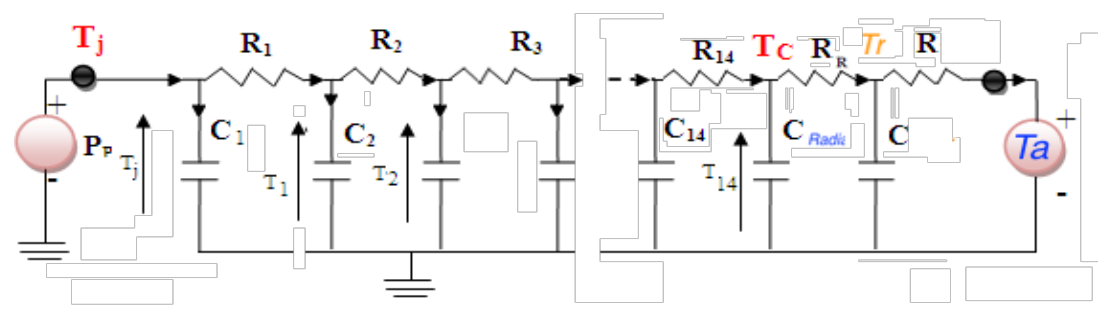

Fig. 2. Thermal model of SiC MOSFET

The RC layers describing the heat flow has as input power loss to be dissipated as an equivalent current source and as second output the ambiant temperature $T_{a}$ represented by voltage source (see Fig. 2). The ouptut of interest is of course the junction temperature $T_{j}$. A $V_{a}=25 \mathrm{~V}$ continuous voltage source correspond to the ambiant air temperature $T_{a}=25^{\circ} \mathrm{C}$. The flow of the dissipated power losses is represented by an input current source $\left(P_{P}\right)$. The junction temperature $T_{j}$ is imposed trough the thermal impedance $Z_{T H}$ between the MOSFET junction and the ambiant air and the dissipated power losses $\left(P_{P}\right)$ by the heat transfer equation $Z_{T H}=\sum_{i=1}^{14} R_{i} *\left(1-\exp \frac{-t}{R_{i} C_{i}}\right)$

$$
T_{j}=T_{a}+P_{P} * Z_{T H}
$$

The thermal MOSFET behaviour, if we consider the thermal state vetor $X_{T}=\left[T_{j}, T_{1}, \ldots, T_{14}, T_{r}\right]^{T}$ can be expressed as

$$
\left\{\begin{array}{c}
T_{1}=T_{j}-R_{1}\left(P_{P}-C_{1} \frac{d T_{J}}{d t}\right) \\
T_{2}=T_{1}-R_{2}\left(P_{P}-C_{1} \frac{d T_{J}}{d t}-C_{2} \frac{d T_{1}}{d t}\right) \\
T_{3}=T_{2}-R_{3}\left(P_{P}-C_{1} \frac{d T_{J}}{d t}-C_{2} \frac{d T_{1}}{d t}-C_{3} \frac{d T_{2}}{d t}\right) \\
T_{4}=T_{3}-R_{4}\left(P_{P}-C_{1} \frac{d T_{J}}{d t}-C_{2} \frac{d T_{1}}{d t}-C_{3} \frac{d T_{2}}{d t}-C_{4} \frac{d T_{3}}{d t}\right) \\
::::::::::::::: \\
T_{N}=T_{N-1}-R_{N}\left(P_{P}-C_{1} \frac{d T_{J}}{d t}-C_{2} \frac{d T_{1}}{d t}-\ldots-C_{N} \frac{d T_{N-1}}{d t}\right) \\
T_{r}=T_{N+1}=T_{N}-R_{R}\left(P_{P}-C_{1} \frac{d T_{J}}{d t}-\ldots-C_{N} \frac{d T_{N}}{d t}\right) \\
T_{a}=T_{r}-R\left(P_{P}-C_{1} \frac{d T_{J}}{d t}-\ldots-C_{N+1} \frac{d T_{N+1}}{d t}-C \frac{d T_{r}}{d t}\right)
\end{array}\right.
$$




\section{Simulations Tests and Model Validation}

The developed model has been implemented in Saber, Pspice and Psim softwares and compared to the experimental curves presented by the SiC MOSFET data sheet for its validation.

\subsection{Saber Simulation Model}

The proposed model is then implemented under Saber software (see Fig. 1). The use of Power MOSFET Tool and the Diode Tool proposed in Saber allow us to extract the SiC MOSFET parameters and get curves using fitting to optimize the estimation errors. The verification of the output characteristic $I_{D S}=f\left(V_{G S}\right)$ with the Saber optimized simulation model, for $T_{j}=25^{\circ} \mathrm{C}$ and $T_{j}=150^{\circ} \mathrm{C}$ as proposed and developed in this work, is shown in Fig. 3.
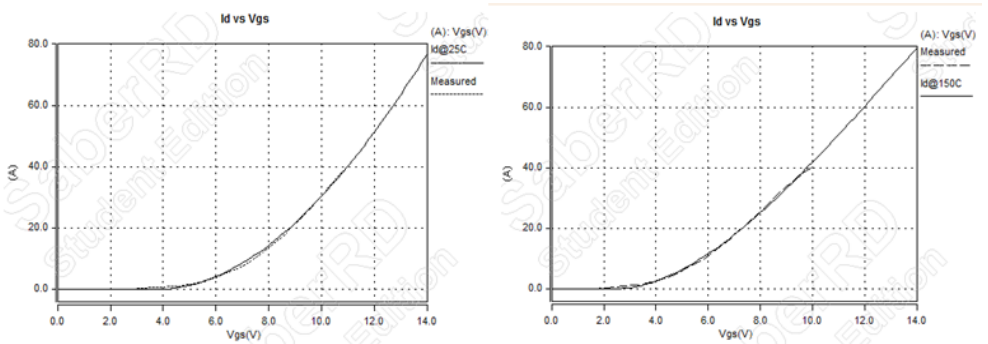

Fig. 3. $I_{D}$ current versus $V_{d s}$

The Fig. 3 compares the variation of the current $I_{D S}$ as a function of the voltage $V_{G S}$ for a voltage $V_{D S}=20 \mathrm{~V}$ and a junction temperature of $25^{\circ} \mathrm{C}$ (left curve) and $150^{\circ} \mathrm{C}$ (right) to the curves got from the datasheet (dotted line).
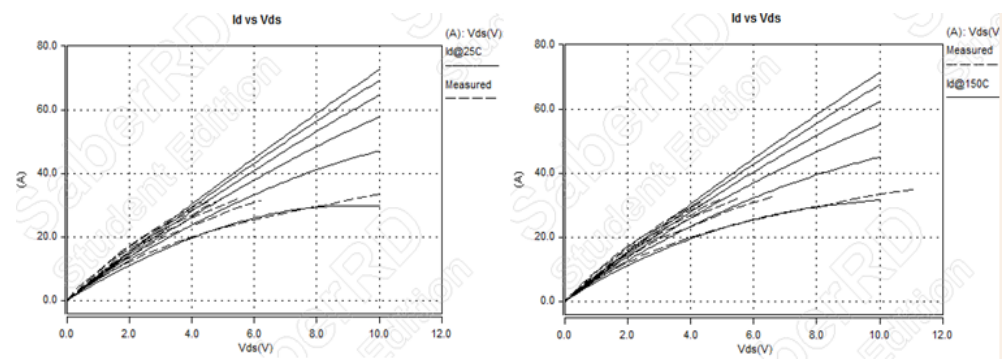

Fig. 4. Id current in function of $V_{D S}$ for different $V_{G S}$ values

The Fig. 4 compares the variations of the current $I_{D S}$ versus $V_{D S}$ for different $V_{G S}$ values and the same junction temperature of $25^{\circ} \mathrm{C}$ (left curve) and $150^{\circ} \mathrm{C}$ (right) to the curves got from the datasheet (dotted line). Among this experiment we got respectively for $25^{\circ} \mathrm{C}$ and $150^{\circ} \mathrm{C}$, a threshold voltage $V_{t h}=3.808 \mathrm{~V}$ and $V_{t h}=2.313 V$, Drain resistance $R_{d}=0.1 \Omega$ and $R_{d}=0.0942 \Omega$, Source resistance $R_{s}=0.01033 \Omega$ and $R_{s}=0.0173 \Omega$ and Gate resistance $R_{g}=4.6 \Omega$ and $R_{g}=4.6 \Omega$ (respectively). 

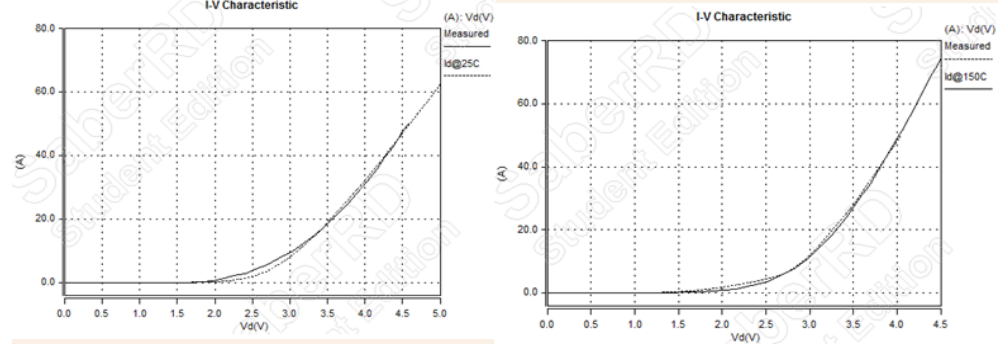

Fig. 5. I-V Charasteristic for $T_{j}=25^{\circ} \mathrm{C}$ and $T_{j}=150^{\circ} \mathrm{C}$

The current versus output voltage (I-V) characteristics of the integrated diode has also been compared, using Diode Tools of Saber software. Results are represented in Fig. 5. The capacitance curves of datasheet have also been fitted to get the MOSFET model parameters. For two $V_{D S}$ values V1 and V2 we got the parameters values summarized in Fig. 1.

\begin{tabular}{ccc}
\hline Parameters & Significance & Values \\
\hline \hline Crrs0 & Max Reverse transfert Capacitance & $780 \mathrm{pF}$ \\
\hline COSS0 & Maximal output capacitance & $1350 \mathrm{pF}$ \\
\hline Ciss0 & Maximal input capacitance & $1775 \mathrm{pF}$ \\
\hline $\mathrm{V} 1$ & $V_{D} S=V_{1}$ & $1 \mathrm{~V}$ \\
\hline $\mathrm{V} 2$ & $V_{D} S=V_{2}$ & $16,3 \mathrm{~V}$ \\
\hline Crss1 & Reverse capacitance at VDS $=\mathrm{V} 1$ & $247 \mathrm{pF}$ \\
\hline COss1 & Output capcitance at VDS $=\mathrm{V} 1$ & $767,5 \mathrm{pF}$ \\
\hline Crss2 & Reverse capacitance at VDS $=\mathrm{V} 2$ & $25,2 \mathrm{pF}$ \\
\hline COSS2 & Output capacitance at VDS $=\mathrm{V} 2$ & $363,1 \mathrm{pF}$ \\
\hline
\end{tabular}

Table 1. MOSFET estimated Parameters

A comparison of the Gate charge, Gate threshold voltage, ON-state resistance and transconductance are given in Table 6 . We then got :

- A very good agreement between the simulations represented by continuous lines and those of datasheet represented by a points,

- For gate voltages $V_{G S}$ lower than $3.8 \mathrm{~V}$, the MOSFET is switched OFF because the condition $V_{G S}$ is not greater than or equal to that transistor threshold $V_{t h}$ Beyond $3.8 \mathrm{~V}$, the MOSFET starts to operate and the current $I_{D S}$ gradually increases.

\subsection{PSpice simulation Model Validation}

Several simulation results obtained, using the model implemented under the Pspice software, were compared with those of the datasheet of the CREE's 


Table 2-1 Verification result of the Saber model of SPW 20N60C 3 MOSFET.
\begin{tabular}{|c|c|c|c|}
\hline & Data sheet & $\begin{array}{c}\text { Model simulation } \\
\text { result }\end{array}$ & Error \\
\hline $\begin{array}{c}\text { Gate charge plateau } \\
\text { voltage }\end{array}$ & $5.5(\mathrm{~V})$ & $5.21(\mathrm{~V})$ & $5.3 \%$ \\
\hline $\mathrm{Q}_{\mathrm{gs}}$ & $11(\mathrm{nC})$ & $10(\mathrm{nC})$ & $9.1 \%$ \\
\hline $\mathrm{Q}_{\mathrm{gd}}$ & $33(\mathrm{nC})$ & $34(\mathrm{nC})$ & $3.0 \%$ \\
\hline $\mathrm{Q}_{\mathrm{g}}$ & $87(\mathrm{nC})$ & $85(\mathrm{nC})$ & $2.3 \%$ \\
\hline Threshold voltage & $\begin{array}{c}2.1(\mathrm{~V}) \text { minimum } \\
3.0(\mathrm{~V}) \text { typical } \\
3.9(\mathrm{~V}) \text { maximum }\end{array}$ & $3.1(\mathrm{~V})$ & \\
\hline On-state resistance & $0.16(\mathrm{ohm})$ & $0.14(\mathrm{ohm})$ & $12.5 \%$ \\
\hline Transconductance & $17.5(\mathrm{~s})$ & $18.8(\mathrm{~S})$ & $7.4 \%$ \\
\hline
\end{tabular}

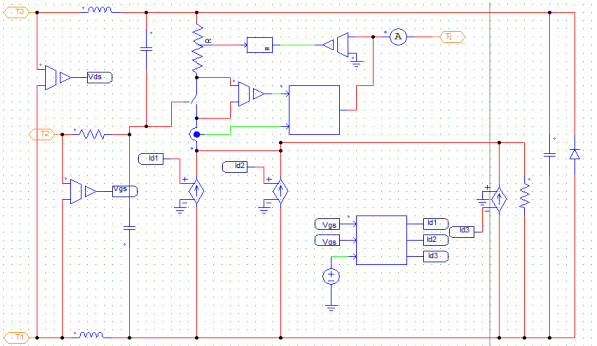

Fig. 6. Comparative results and the Psim model

MOSFET [9]. The model scheme is given in Fig. 7 with the parameters estimated (under Pspice tests) from datasheet. We can note that the resistances $R_{d}$ and $R_{s}$ are small and have been neglected.

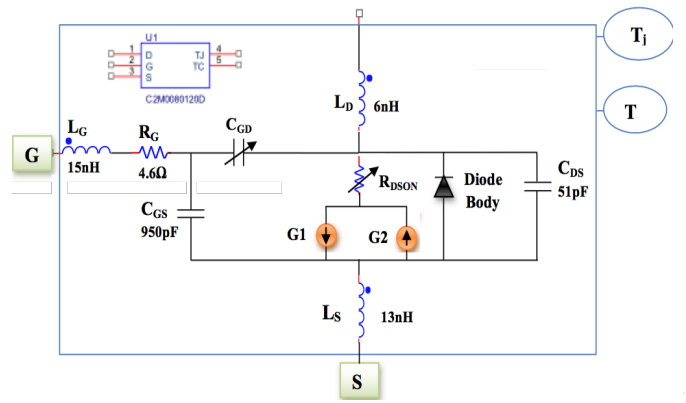

\begin{tabular}{c|c}
\hline Parameters & Values \\
\hline \hline$L_{D}$ & $6 n \mathrm{H}$ \\
\hline$L_{G}$ & $15 n \mathrm{H}$ \\
\hline$L_{S}$ & $9 n \mathrm{H}$ \\
\hline$R_{G}$ & $4,6 \Omega$ \\
\hline$C_{G S}$ & $950 \mathrm{pF}$ \\
\hline$C_{D S}$ & $51,93 p F$ \\
\hline$C_{G D}$ & $161,7 p F$ \\
\hline
\end{tabular}

Fig. 7. Pspice Sic MOSFET C2M0080120D and Parameters

The Fig. (8) below show good behaviour of the electrothermal model proposed in this work. Fig. 8 represents the variation of the Drain-Source current $\left(I_{D S}\right)$ as a function of the voltage at the output of the SiCMOSFET $\left(V_{D S}\right)$ for different Grid-Source voltage values $\left(V_{G S}\right)$ and a temperature of $25^{\circ} \mathrm{C}$. It appears that there is a very good agreement between the simulation results, represented by lines, and those of datasheet, represented by poinctual bars.
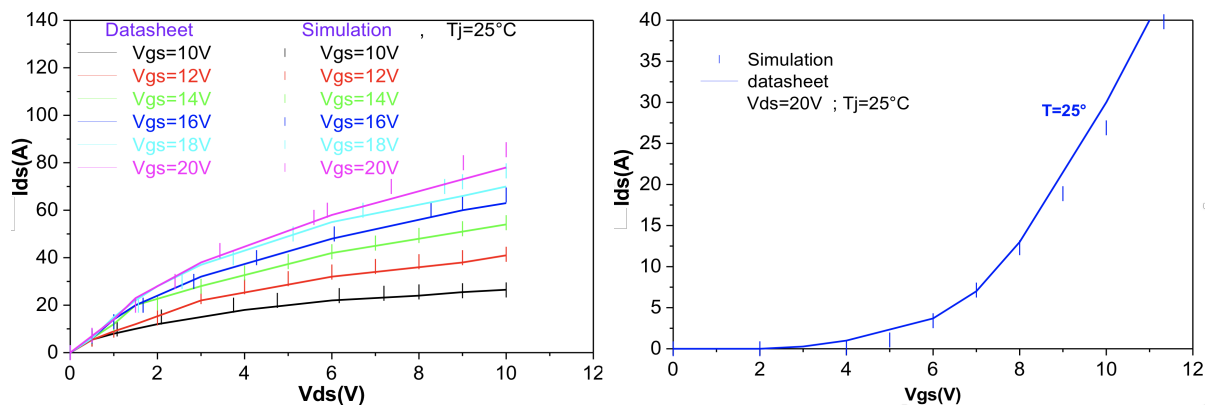

Fig. 8. Variation of $I_{D S}$ current versus $V_{D S}$ for different values of $V_{G S}$ and Drain-Source current Ids versus $V_{G S}$ 
Fig. 8 the variation of the current $I_{D S}$ as a function of the voltage $V_{G S}$ for a voltage $V_{D S}=20 \mathrm{~V}$ and a temperature of $25^{\circ} \mathrm{C}$. We can note a very good agreement between the simulation results represented by continuous lines and those of detasheet represented by dotted bars. For voltages $V_{G S}<4 \mathrm{~V}$, the MOSFET is not controlled because the condition $V_{G S}<V_{t h}$, the treshold condition is not verified. Beyond $4 \mathrm{~V}$, the transistor start to operate and the current $I_{D S}$ gradually increases. Fig. 9 show the thermal effect on the Drain-Source resistance $\left(R_{D S o n}\right)$ compared to the datasheet characteristic, for $I_{D S}=50 \mathrm{~A}$ and $V_{G S}=20 \mathrm{~V}$. It appears that the electro thermal model developed in this work has a high accuracy and is close to actual operating (datasheet) up to very high temperatures $\left(150^{\circ} \mathrm{C}\right)$.

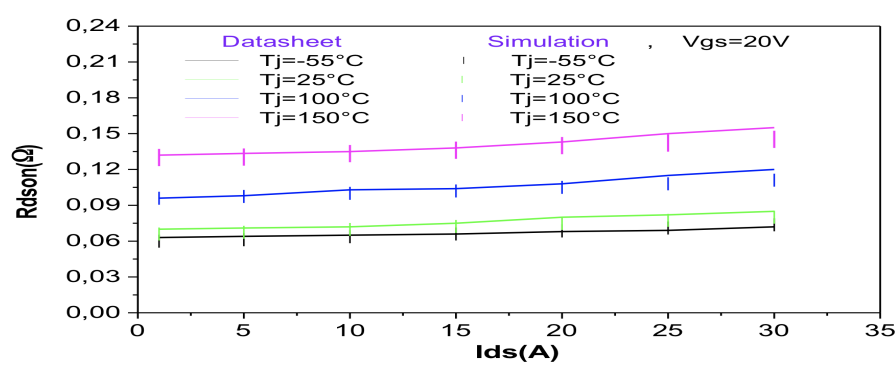

Fig. 9. $R_{D S o n}$ Variations in function of the junction temperature

In summary, the electric model developed, under Pspice, during this work has considerable precision. This allows us subsequently to use this simulation model in the power electronics to clearly show these performance and advantages over silicon transistors. Although the CREE model fairly accurately represents the evolution of $R_{D S o n}$ in function of the junction temperature, it has some discrepancy with the datasheet. However, with our simulation model, it is easy to see a better superposition between the two curves by adjusting the coefficients mentioned in Table 1.

\subsection{Psim simulation Model Validation}

The proposed model is implemented in Psim software as described by the Fig. (6). The improvements in the simulation model need additional adjustments of the device characteristics and computation parameters such as variable simulation step size which is used for the convergence rapidity. For our SiC MOSFET, we use the parameters that have been extracted from the data sheet (see table 7). The Drain and Source resistances have been neglected. The Fig. 10 shows the variation of $I_{D S}$ in function of the drain-source voltage $V_{D S}$. It compares the Drain-Source current $\left(I_{D S}\right)$ versus the MOSFET output voltage $\left(V_{D S}\right)$ for several Gate-Source voltages $\left(V_{G S}\right)$ under a temperature of $25^{\circ} \mathrm{C}$. The simulated characteristics are then compared to the data sheet values and curves. Simulation results (continuous lines) are in good agreement with the data sheet values (dots).

The Fig. 10 shows the variation of $I_{D S}$ in function of the Gate-Source voltage $V_{G S}$ for the junction temperatures of $25^{\circ} \mathrm{C}$ and $150^{\circ} \mathrm{V}$. We can note that for 

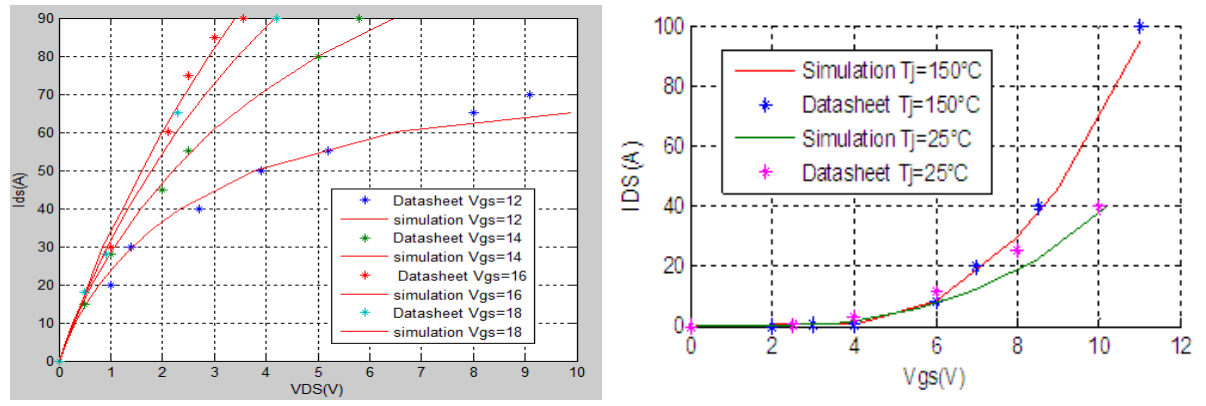

Fig. 10. $I_{D S}$ versus $V_{D S}$ for different $V_{G S}$ values and $I_{D S}$ versus $V_{G S}$ for $T_{j} 25^{\circ} \mathrm{C}$ and $150^{\circ} \mathrm{C}$

$V_{G S}$ values less than $4 \mathrm{~V}$, the MOSFET is not controlled because the threshold voltage $V_{t h}$ is not reached. When the MOSFET start operation $V_{G S}>V_{t h}>4 V$, and then the current $\mathrm{I}_{\mathrm{DS}}$ increases gradually with $V_{G S}$. The results are in good agreement.

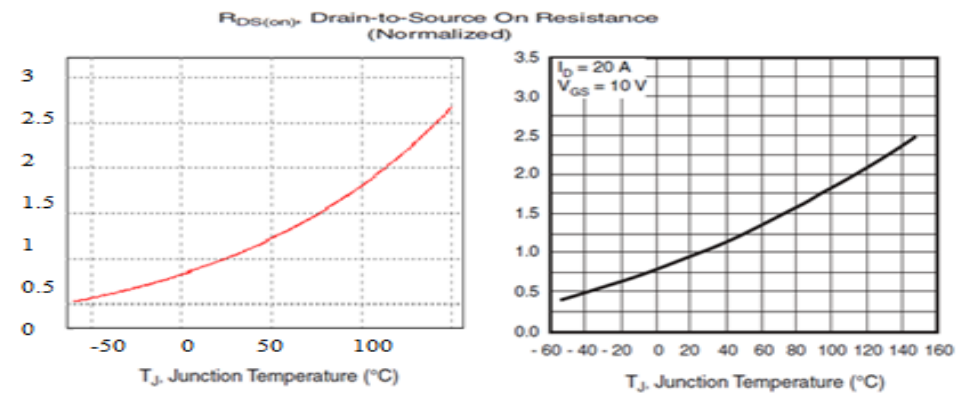

Fig. 11. Variation of $R_{D S o n}$ versus the temperature $T_{j}$

The Fig. 11 shows the simulated and the actual Drain-Source resistance $\left(R_{D S o n}\right)$ in function of the temperature variation $T_{j}$, for a current equal to $I_{D S}=50 \mathrm{~A}$ and voltage $\mathrm{V}_{\mathrm{GS}}=20 \mathrm{~V}$. The obtained curves are very close in a wide temperature range (up to $\mathrm{T}=150^{\circ} \mathrm{C}$ ). We observe that the result obtained is similar to the datasheet, particularly in the interval $\left[0^{\circ} \mathrm{C}, 150^{\circ} \mathrm{C}\right]$.

\section{Conclusion}

A new model of SiC Power MOSFET is proposed in this paper. This model is implemented successfully under Psim, Pspice and Saber softwares and then have been tested and optimized for numerical circuit design and simulation. The Characteristics of the MOSFET simulation models (on-state resistance, threshold voltage, and transconductance, etc...) has been compared to actual characteristics given by manufacturer's data sheet in Psim, PSpice and Saber.

The proposed electrothermal model is very accurate and able to describe the dynamic behavior of the SiC MOSFET with a very good precision. Owing to our last results, it is shown that the electrothermal model developed on Psim, Pspice 
an Saber has a high accuracy and is close to the optimum operating conditions presented in the datasheet. This simulation model of SiC power MOSFET is easy to use in numerical design and prototyping of electric circuits and simulations. The future work of our staff will be on nonlinear and robust control of a power circuit including the SiC MOSFETs.

\section{Acknowlegment}

This research is activity is held by the SASV group of the LSIS- UMR CNRS 7296 and co funded by the BPI in an FUI project. Special aknowledgements are addressed to all the PFC Ranger project partners. The authors (member R22190) would like to thanks also Europractice (http://www.europractice.stfc.ac.uk/ )

\section{References}

1. H. C. Foong, Y. Zheng, Y. K. Tan, and M. T. Tan, "Fast transient integrated digital DC DC converter with predictive and feedforward control," vol. 59. 1

2. N. Bejoy, N. Pushpakaran, B. Stephen, B. Bayne, G. Wang, and J. Mookken, "Fast and accurate electro-thermal behavioral model of a commercial sic 1200v, 80 mohm power mosfet," IEEE Transactions on Electron Devices, january 2015. 1

3. B. Pushpakaran, S. Bayne, G. Wang, and J. Mookken, "Fast and accurate electrothermal behavioral model of a commercial sic 1200v 80 mohms," IEEE Pulsed Power Conference (PPC), December 2015. 1

4. B. Wang and Y. Ma, "Research on the passivitybased control strategy of buck-boost converters with a wide input power supply range," $n$ Power Electr. for Distrib. Generat. Syst, vol. 13, 2010. 1

5. E. Vittoz, C. C. Enz, and F. Krummenacher, "A thermal characterization of power transistors semiconductor," vol. 11. 1

6. Stefanović, Danica, and M. Kayal, "Bsim to ekv conversion," 01 Bsim To Ekv Conversion. 1

7. L. Juejing, K. Sun, W. Hongfei, Y. Xing, and L. Huang, "Modeling of sic mosfet with temperature dependent parameters and its applications," in Twenty-Eighth Annual IEEE Applied Power Electronics Conference and Exposition, A. 2013, Ed., 2013, pp. 540-544. 2.2, 2.2

8. F. Bilbao, B.Argenis, and L.Stephen, "Pspice modeling of silicon carbide mosf ets and device parameter extraction," in IEEE InternationalPower Modulator and High Voltage Conference,. PMHVC 2012, 3-7 June 2012, pp. 776-779. 2.2, 2.2, 2.3

9. CREE, "Sic power mosfet cmf20120d datas-sheet and application note," http://www. cree. com/products/pdf/CMF20120D. pdf, 2015. 2.2, 2.3, 2.3, 3.2

10. T. M. Nutt, A. Hefner, H. Mantooth, J. Dultiere, D. Berning, and R. Singh, "Parameter extraction sequence for silicon carbide schottky, merged pin schottky and pin power diode models," Power Electronics Specialists Conference, vol. 3, February 2002. 2.2

11. N. K. M'Sirdi, A. Naamane, K. Frifita, M. Boussak, and E. Baghaz, "State space models nltv for electro-thermal behaviour of a power sic mosfet," submitted to ICEERE2018, Saidia Oujda Morroco, April 2018. 2.2 